\title{
Wireless Sensor Network for Rainfall Measurement using a Tipping Bucket Rain Gauge Mechanism
}

\author{
Osemwegie Omoruyi \\ Dept. of Electrical \& Information Engineering \\ Covenant University, \\ Ota, Ogun state, Nigeria. \\ osemwegie.omoruyi@cu.edu.ng \\ Okereke Chinonso \\ Department of Electrical and Information Engineering, \\ Covenant University, \\ Ota, Ogun state, Nigeria. \\ okereke.chinonso@covenantuniversity.edu.ng \\ Adeyinka A. Adewale \\ Dept. of Electrical \& Information Engineering \\ Covenant University, \\ Ota, Ogun state, Nigeria. \\ ade.adewale@covenantuniversity.edu.ng
}

\author{
Samuel N. John \\ Dept. of Electrical \& Information Engineering \\ Covenant University, \\ Ota, Ogun state, Nigeria. \\ samuel.john@covenantuniversity.edu.ng \\ Okonigene Robert \\ Department of Electrical and Electronic Engineering, \\ Ambrose Alli University, \\ Ekpoma, Edo State, Nigeria. \\ robokonigene@aauekpoma.edu.ng \\ Kennedy O. Okokpujie \\ Dept. of Electrical \& Information Engineering \\ Covenant University, \\ Ota, Ogun state, Nigeria. \\ Kennedy.okokpujie@covenantuniversity.edu.ng
}

\begin{abstract}
Distributed wireless sensor networks are a new technology that can provide processed real-time field data from sensors that are physically distributed in the field. This study describes a wireless distributed sensor network that gives precision rainfall detection and measurement. Rain fall measurements can be done using a variety of means. One of such means is using a Tipping Bucket Rain Gauge Mechanism. In order to accomplish this, sensor nodes consisting of water level sensors and a wireless transceiver which transmits measured data is attached to the rain gauge. The measured data or signal from the rain gauge is transmitted to a receiver or collector point. The collector point is connected to a computer system (central station). Data retrieved is then displayed by the means of a GUI created customarily for it at the central station. The result of the research work shows a significant accuracy in the rain fall measurement recorded.
\end{abstract}

Keywords-Wireless Sensor Network, rain gauge, tipping buket, measurement.

\section{INTRODUCTION}

The use of distributed wireless sensor networks has a wide range of applications in everyday life. Distributed wireless sensor networks are a more recent technology applied globally to situations where physical parameters are being studied. This includes natural phenomena like Temperature, Atmospheric pressure, Wind speed, Light intensity, Earthquake and Seismic activity and Rainfall. It generally requires a centrally located receiving unit which gets data from multiple sensor nodes installed in the environment (electronic sensing devices). Some of the areas where WSNs are being used globally are Agriculture and Meteorological studies especially for rain measurement. Rain measurement is one of many factors considered in studying weather and climate in a given geographic location. Some of this climate studies are done using a rain gauge. The Rain gauge is a meteorological instrument for determining the amount of rainfall or precipitation in a geographic location over a given time interval or period. It is usually measured in millimetre $(\mathrm{mm})$ and it is taken as an estimate of the total rainfall per square metre $\left(\mathrm{m}^{2}\right)$. Rain measurement using a rain gauge is done using a number of configuration and setups but the basic example is that of a circular funnel with diameter which is 10 times the crosssectional area of the graduated cylinder as shown in Figure 1a and Figure $1 \mathrm{~b}$. The funnel collects the rain into the graduated measuring cylinder that can record up to $25 \mathrm{~mm}$ of precipitation, where one millimetre of the measured precipitation is the equivalent of one litre of rainfall per meter square [1].

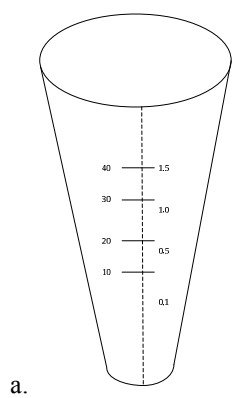

b.

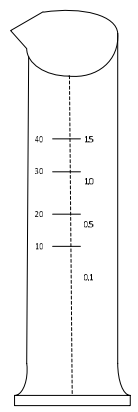

Fig. 1. a. Traditional rain gauge measurement. b. Illustration of a graduated cylinder or standard or direct reading gauge. 
Rain measurement has evolved over time such that even though the rain gauge is still in use as an instrument used to measure rainfall. The radars $[3,7]$ and satellites system [6] are also used for the same purpose. However, radars and satellites are not common because not every country, locality or institution may have access to these technologies based on cost. Compared to these other instruments, the rain gauge produces relatively accurate point measurements of precipitation and is cheaper. However, the accuracy of manually operated rain gauges is user-dependent, this means that it is as accurate as the person checking the rain gauge, taking the readings, emptying the gauge, and resetting it. A number of errors can occur during and after measurement. First of all, when taking the readings, there are errors due to parallax and due to the fluid meniscus (the curved surface of a still liquid in a tube). Secondly, when emptying the graduated cylinder to take a new measurement, some water might still be left in it and this could also lead to errors in measurement because the amount of precipitation will look more than it actually is The implementation of rainfall measurement using electronic sensors eliminates these errors because the system will no longer depend on the user for checking the gauge and recording the data. Hence, the purpose of this project is simply to create a more accurate and less userdependent system of using wireless sensor network/system in measuring the intensity of rainfall with a tipping bucket rain gauge.

\section{OVERVIEW OF RAIN MEASUREMENT SySTEMS}

The According to [2] there are four types of rain gauges. These types of rain gauges can be further classified into two:

- Manual Rain Gauge: This is the most common instrument for rainfall measurement. It is a circular funnel with a diameter of $203 \mathrm{~mm}$ which collects rain into a graduated cylinder and it is usually placed on the ground with no nearby objects to alter the wind flow.

- Automatic Rain Gauge: This is also called a Tipping Bucket Rain Gauge. It is usually used in automatic weather stations to record rainfall. It has 2 buckets on a pivot and once the equivalent of $0.2 \mathrm{~mm}$ of rainfall has been collected in one of the buckets, it is tipped (emptied). As one bucket is emptied, the other starts to fill and counter records the number of tips. More emphasis shall be on the automatic rain gauge because it is the rain gauge used in this project for rain measurement.

\section{A. Types of Gauges}

- Graduated Cylinder: The standard rain gauge was developed at the beginning of the twentieth century and consists of a graduated cylinder ( $2 \mathrm{~cm}$ diameter) as seen in figure $1 \mathrm{~b}$ in which the collection funnel drains. Graduated cylinder gauges use scales from $0.2 \mathrm{~mm}$ to $25 \mathrm{~mm}$ [2]. When the main unit is filled with water, the spillover is directed to a larger container. The total rainfall is indicated by the total height of rain reached in the cylinder. The main errors that arise with this rain gauge is that it is user-dependent, this means that it is as accurate as the person checking the rain gauge, taking the readings, emptying the gauge, and resetting it and this leads to a lot of errors in the measurement. When taking the readings, there are errors due to parallax and due to the fluid meniscus (the curved surface of a still liquid in a tube). Errors can also occur when emptying the graduated cylinder to take a new measurement, some water might still be left in it and this could also lead to errors in measurement because the amount of precipitation will look more than it actually is.

- $\quad$ Tipping Bucket: This rain gauge is a simple mechanical device that measures rainfall in increments of 0.254 $\mathrm{mm}$, or on one tip, at a discrete point location on the earth's surface [5].The tipping bucket gauge is made of collector funnel that collects and channels the precipitation into a small seesaw-like container [2]. The water collects inside one of the buckets that flip or 'tips' horizontally when it exceeds a desired weight, and discharges through the force of gravity [2]. With the use of a wireless transceiver, rainfall data can be logged at each 'tip'. Figure 2 shows a labeled diagram of a tipping bucket rain gauge. Tipping bucket rain gauges are subject to a number of errors as detailed in [6].

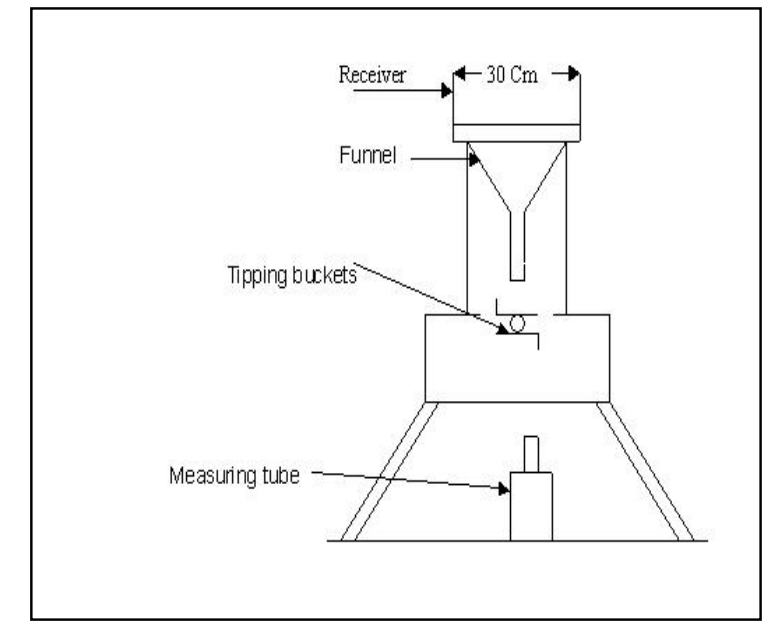

Figure 2: Tipping rain guage

- Weighing Rain Gauges: Weighing operates using the principle of weighing the water collected by the instrument [11]. With the advance of technology the data is collected by a sensor and converted into numerical values directly into a logger [2]. This type of rain gauge can also measure solid precipitation, such as snow and hail [2]. However, these weighing rain gauges are more expensive to maintain compared to the tipping buckets.

- Optical Rain Gauges: Rainfall is measured by detecting optical irregularities [2]. Optical Rain Gauges sense raindrops passing through a light beam and convert the scintillating signal into rainfall intensity [10]. However, the measurement performed on the 
optical rain gauges shows poorly in measuring solid precipitation like hail or snow.

\section{Methodology}

The system design contains details on how the device was designed and built to fulfill the objectives identified as stated in the introduction of this work. Also, the methodology contains details of the design and construction of the final model of the system. The research project is made up of the following:

\section{A. Mechanical Design:}

This project aims to fix the limitations found in the methods used in measuring rainfall today. As aforementioned, these include the manual and tipping bucket rain gauges. These limitations includes the fact that the manual rain gauge was too user dependent and the tipping bucket rain gauge, though less user dependent, was less accurate due to its mechanical nature. To fix these issues, this project will incorporate the tipping bucket rain gauge to make it less user dependent. This is where the mechanical part of this project is used. This is done so that the user of the end device can leave the system for a long period, say a month, without having to go to the field to take measurements or to empty the rain gauge (as in manual rain gauge). As for the accuracy problem that comes with using this method, we fix this by using water level sensors. The water level sensor measures the level of water in the rain gauge so that we have a more accurate value and not an estimation.

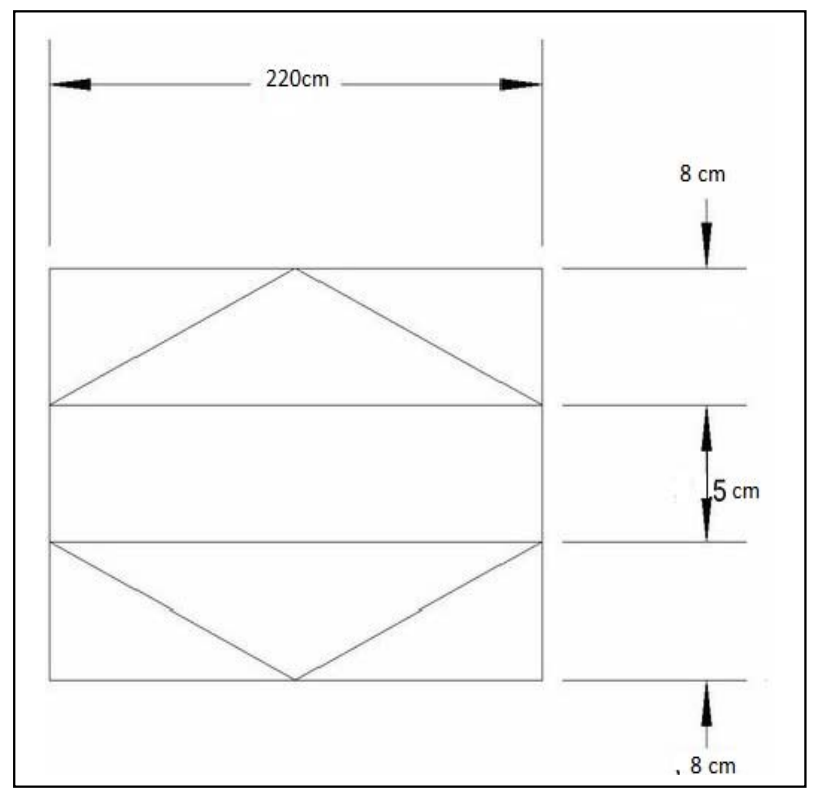

Fig. 2. Plan of the tipping bucket rain gauge

\section{B. Electrical Design:}

This is the area where brainstorming was really required, because it involved programming the microcontroller which is basically the brain of the project. This is because it is involved in every aspect of the project from collecting data for the water level sensors to the wireless transmission of data. The ez430rf2500 board [8] containing the MSP430F2274 microcontroller and a CC2500 transceiver were selected for its transmitterreceiver (transceiver) capability as the data transmission units for each sensor. The ez430-rf2500 $\mathrm{T}$ boards come as standalone transceiver units with power supplied from 2 batteries. The radios transmit and receive information at frequencies of $2.4 \mathrm{GHz}$. A 9v-5v power supply system was devised to supply the voltage needed for the operation of the water level sensors.

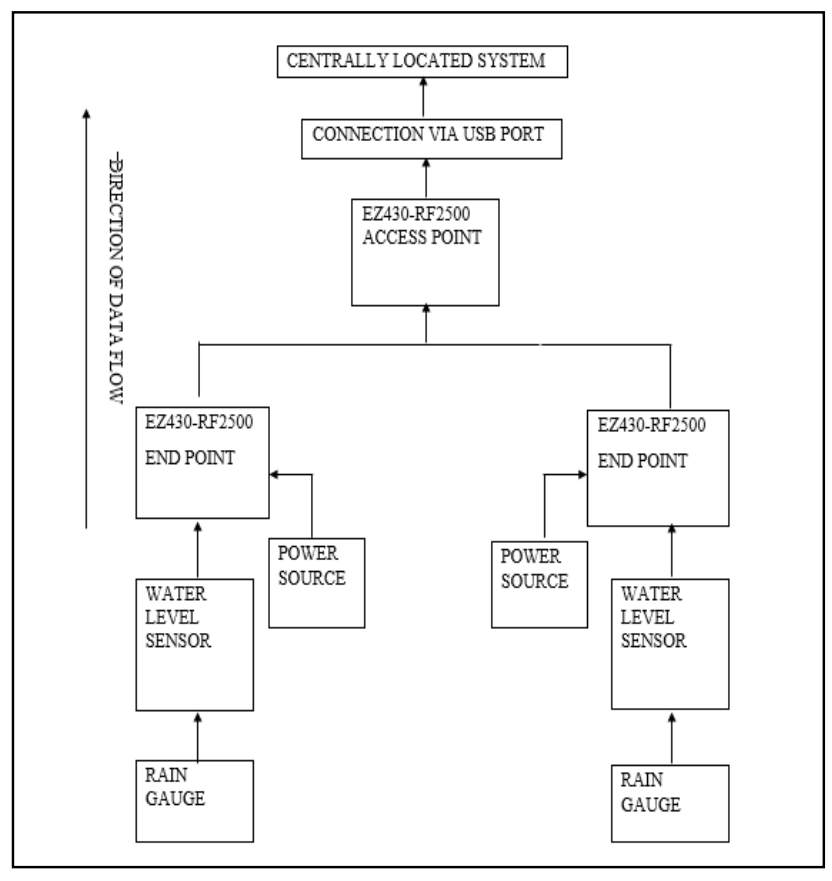

Fig. 3. Block diagram of the system

The 10 bit ADC Conversion Formula is stated below

$$
N_{A D=}=1023 \times \frac{v_{n}-v_{R-}}{V_{R_{1}}-v_{R}}
$$

Where $\mathrm{N}_{\mathrm{ADC}}$ is the value in bits of the above ratio and $\left(\mathrm{V}_{\mathrm{R}+}\right.$ and $\mathrm{V}_{\mathrm{R}-)}$ are the reference voltage levels of the ADC. Given an arbitrary measured rainfall in a container of $\mathrm{P} \mathrm{mm}$,

$$
V_{\text {in }}=\frac{P}{L} * V_{\text {th }}
$$

Where $\mathrm{V}_{\text {th }}$ is the maximum or threshold voltage of the water level sensor and $\mathrm{L}$ is the length of the container. Therefore, $\mathrm{N}_{\mathrm{ADC}}$ and $\mathrm{L}$ can be calculated as follows:

$$
\begin{aligned}
& N_{A D C}=1023 \times \frac{\left(\frac{P}{L} * V_{t h}\right)-V_{R-}}{V_{R+}-V_{R-}} \\
& L=\frac{1023\left(P V_{\text {sh }}\right)}{V_{R+}-V_{R-}+1023 V_{R-}}
\end{aligned}
$$




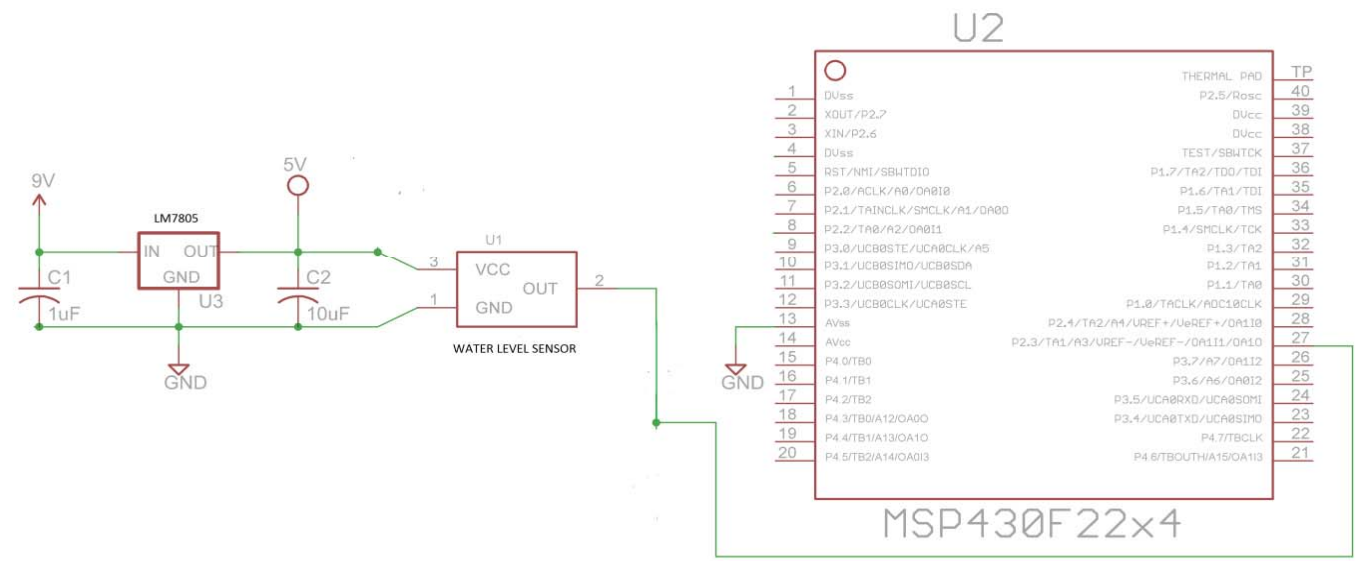

Fig. 4. Schematic circuit otlay of the water level sensor connected to the MSP430F2274 microcontroller of the ez430 rf2500 board

Software Design:

The sensor nodes and the central units interact continuously over a period of time during the measurement or sampling of data as shown in Figure 6. The use of callback functions when a transmission is sensed by the central unit allows for the remote processing of data coming from the sensor nodes. The central unit is kept in a no operation mode (waiting) period pending when the next packet is sent by sensor nodes. The Central unit is configured to switch channels during this period therefore alternating between sensor nodes. Channels are divided into $200 \mathrm{KHZ}$ spaces between $2430 \mathrm{GHz}$ and $2475 \mathrm{GHz}$. Channels can be selected by altering register values of the transceiver units.

\section{RESULT}

The coding implementation of this project involved the connection of the water level sensors with the microcontroller as shown in figure 5, this was done so as to enable the wireless transmission of the acquired data and the real-time display of the water level sensors data stream. The code needed for the ez430-rf2500 boards was done in c. It involved the sampling of the analogue output of the water level sensor and then the digital quantizing of its output values with the aid of the 10 bit ADC provided on the ez430-rf2500 boards. Values are relayed via transceiver unit and are received by a third transceiver unit connected to a central station (Laptop computer unit). C\# GUI using Oxyplot libraries [9] was designed to show a relevant chart of the raw data readings as shown in figure 8 .
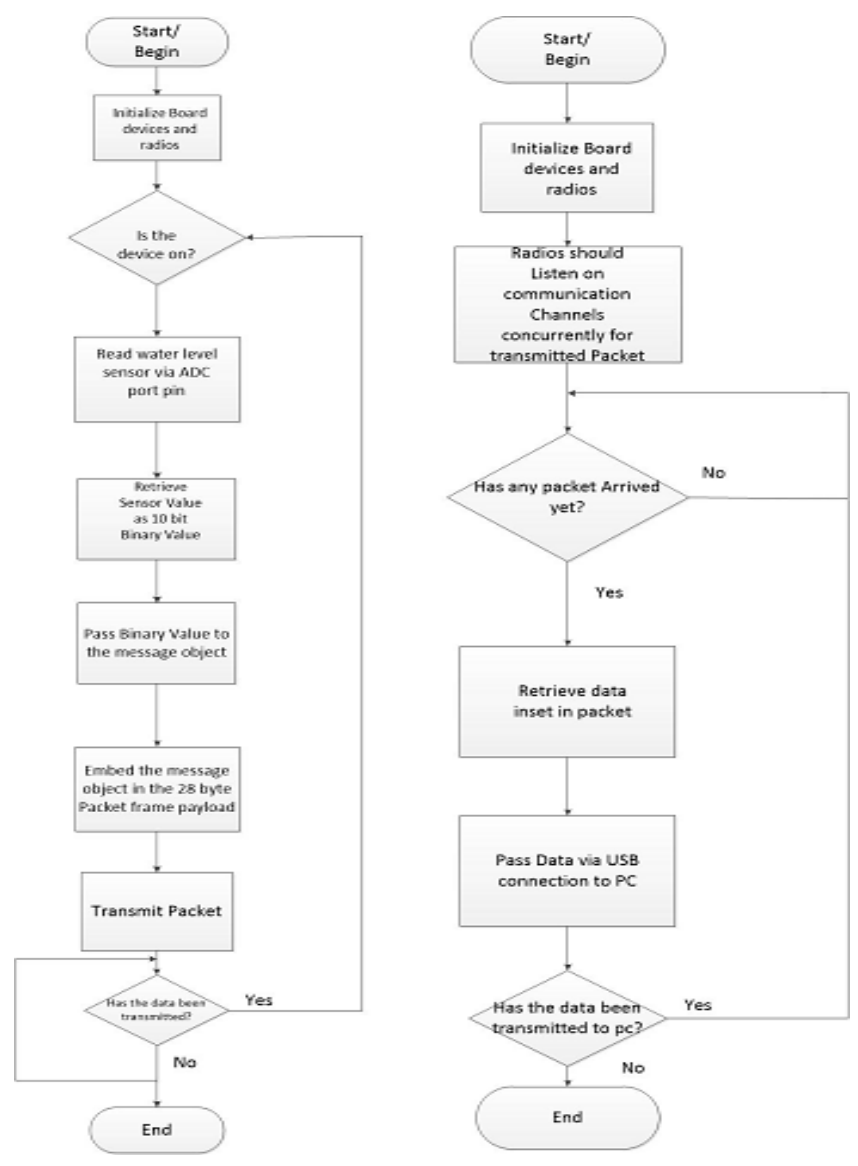

Fig. 5. Flowchart showing the dataflow from a sensor node to the central unit 


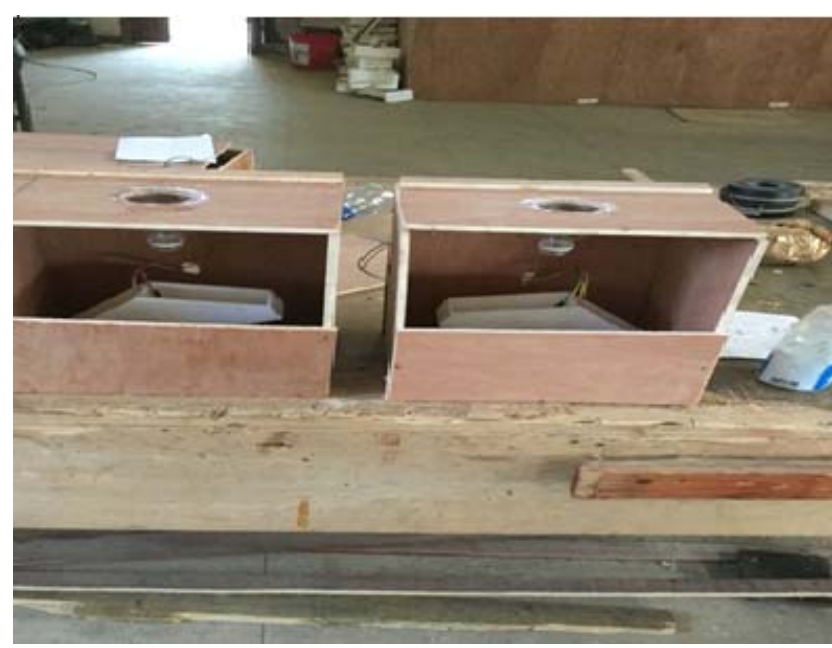

Fig. 6. Picture of the finished rain gauge

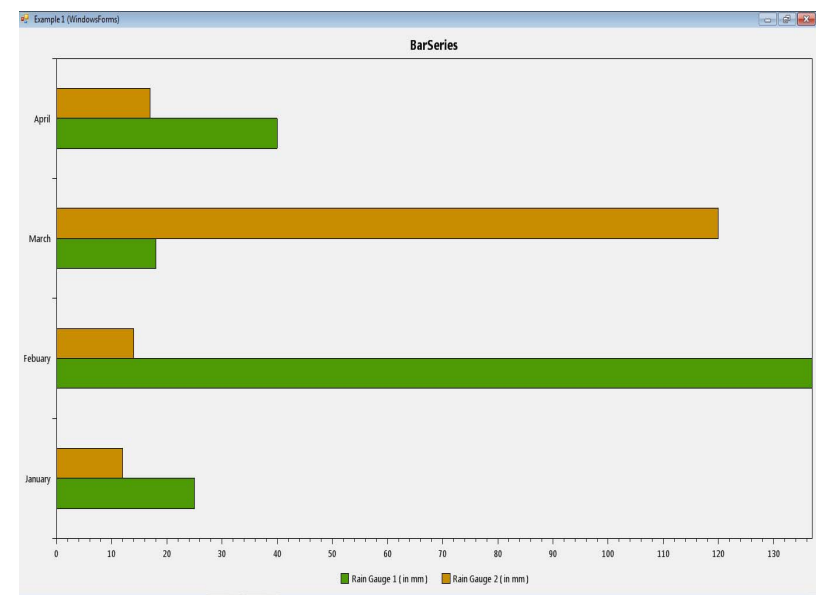

Fig. 7. Oxyplot charts for display of obtained readings in development

\section{CONCLUSION}

The devising of more inexpensive mid-range and long range radio systems for WSNs will make them of more practical and robust use in studying rainfall over a wide geographic area. The work could also do well to integrate a database system at the sensor level and at the central location level to serve as repository where past readings can be obtained for analysis. The GUI designed could also integrate more algorithms and charts for easy to be understood presentation and more in depth analysis.

\section{ACKNOWLEDGMENT}

This paper is sponsored by Covenant University, Ota, Ogun State, Nigeria.

\section{REFERENCES}

[1] "Weather facts: Rain gauge - weather UK," in weather online, weatheronline.co.uk, 1999.

[2] S. Alton, J. Jacobs, and B. Stewart, "El Niño still growing," in Guides, NW Climate, 2016. [Online]. Available: http://www.nwclimate.org/guides/how-to-use-rain-gauge/.

[3] T. Harrold, "The Measurement Of Rainfall Using Radar", Weather, vol. 21, no. 7, pp. 247-258, 1966

[4] G. Ciach, "Local Random Errors in Tipping-Bucket Rain Gauge Measurements", Journal of Atmospheric and Oceanic Technology, vol. 20, no. 5, pp. 752-759, 2003.

[5] J. Wang, B. Fisher and D. Wolff, "Estimating Rain Rates from TippingBucket Rain Gauge Measurements", Journal of Atmospheric and Oceanic Technology, vol. 25, no. 1, pp. 43-56, 2008.

[6] T. V. Omotosho and C. O. Oluwafemi, "One-minute rain rate distribution in Nigeria derived from TRMM satellite data," Journal of Atmospheric and Solar-Terrestrial Physics, vol. 71, no. 5, pp. 625-633, 2009.M. Young, The Technical Writer's Handbook. Mill Valley, CA: University Science, 1989.

[7] R. Doviak, "A Survey of Radar Rain Measurement Techniques", Journal of Climate and Applied Meteorology, vol. 22, no. 5, pp. 832849, 1983.

[8] M. Morales and Z. Shivers, "Wireless sensor monitor using the ez430rf2500," App. Report. SLAA378D, 2007.

[9] “OxyPlot." [Online]. Available: http://www.oxyplot.org/. [Accessed: 24Sep-2017]

[10] I. Strangeways, "A history of rain gauges," Weather, vol. 65, no. 5, pp. 133-138, 2010.

[11] J. A. Nystuen, J. R. Proni, P. G. Black, and J. C. Wilkerson, "A comparison of automatic rain gauges," Journal of Atmospheric and Oceanic Technology, vol. 13, no. 1. pp. 62-73, 1996. 